\title{
Multivariate Treatment of LIBS Data of Prehistoric Paintings
}

\author{
Flávia de S. L. Borba, ${ }^{a}$ Juliana Cortez, ${ }^{b}$ Viviane K. Asfora, ${ }^{c}$ Celio Pasquini, ${ }^{b}$ \\ Maria Fernanda Pimentel, ${ }^{*, d}$ Anne-Marie Pessis ${ }^{e}$ and Helen J. Khoury ${ }^{c}$
}

${ }^{a}$ Departamento de Química Fundamental, Universidade Federal de Pernambuco, 50740-540 Recife-PE, Brazil

${ }^{b}$ Instituto de Química, Universidade Estadual de Campinas, 13083-970 Campinas-SP, Brazil

'Departamento de Engenharia Nuclear, Universidade Federal de Pernambuco, 50740-540 Recife-PE, Brazil

${ }^{d}$ Departamento de Engenharia Química, Universidade Federal de Pernambuco, 50740-521 Recife-PE, Brazil

ePrograma de Pós-Graduação em Arqueologia, Universidade Federal de Pernambuco, 50670-901 Recife-PE, Brazil

Dois fragmentos de pinturas rupestres pertencentes a dois sítios arqueológicos brasileiros, sendo um no estado do Piauí (Sítio Toca da Extrema II) e outro no estado do Rio Grande do Norte (Sítio arqueológico Xique-Xique), foram analisados por LIBS (espectroscopia de emissão em plasma induzido por laser). Um instrumento construído no laboratório (laser Nd:YAG, $1064 \mathrm{~nm}$, $5,2 \mathrm{~ns}$ ), contendo um policromador echelle, foi empregado para a aquisição dos espectros. Estudos preliminares envolvendo uma pintura realizada sobre uma tela de madeira contendo diferentes camadas de material foram realizados para determinar a melhor energia do pulso de laser. Para cada fragmento de pintura, foram realizados 8 pulsos sucessivos em 16 locações diferentes, sendo 8 locações sobre a pintura e 8 sobre o substrato. Neste trabalho, foi demonstrado que a utilização de técnicas multivariadas é indispensável devido à grande complexidade dos espectros obtidos durante estudo de profundidade de amostras arqueológicas.

Laser-induced breakdown spectroscopy (LIBS) was employed in the study of two fragments of prehistoric rock wall paintings found at two Brazilian sites: in Piauí State (Toca Extrema II) and in Rio Grande do Norte State (Xique-Xique). A time-resolved echelle based LIBS system assembled in the laboratory (laser Nd:YAG, $1064 \mathrm{~nm}, 5.2 \mathrm{~ns}$ ) was employed for spectral acquisition. Preliminary depth profile studies were carried out in surrogate samples of a multilayer painting on wood to determine the best energy for the laser pulse. For each fragment of wall painting, the depth profile composition was investigated by firing 8 successive laser shots at each of 16 locations ( 8 in the area of pigment and 8 in the area of substrate). It is demonstrated in this work that the use of multivariate techniques is compulsory due to the high complexity of the spectral data obtained from depth profile studies of the archaeological samples.

Keywords: prehistoric paintings, principal component analysis, LIBS, laser-induced breakdown spectroscopy, depth profile

\section{Introduction}

Laser-induced breakdown spectroscopy (LIBS) is an attractive technique for archaeological analysis because it is nearly non-destructive and does not require sample

*e-mail: mfernanda.pimentel@gmail.com,mfp@ufpe.br preparation. It also provides rapid multi-element analysis, even for the light elements, and the spatial resolution is almost microscopic. Depth profile analysis is possible and the use of portable instrument allows for in situ analysis of large and unmovable samples. ${ }^{1-3}$ LIBS utilizes a pulsed laser focused on a small spot on the surface of the sample. ${ }^{4}$ The high irradiance (energy per area) produces vaporization 
of a tiny quantity of the sample constituents and promotes the formation of a plasma of high temperature capable of atomize and/or ionize most of the chemical elements present in the sample, which are excited to higher electronic energy levels. After relaxation (and an initial intense continuous emission), atomic and ionic emissions at specific wavelengths for each element occur. The emitted radiation is collected by a lens or optical fiber, dispersed into its wavelengths and measured by a detector. In recent years, the technique has been used for a wide variety of analytical problems (e.g., environmental monitoring, industrial process control and analysis of explosives, gunshot residue, plant materials, geochemical and archaeological samples, etc.). ${ }^{5-12}$

In the Northeast of Brazil, there are many archaeological sites, where prehistoric paintings are found on the walls of open caves. These prehistoric paintings are characterized by similar features: animals with round shapes for bodies, stick figures in movement and similar emblematic scenes. They can be found in archaeological sites located thousand miles from each other. Several sites stand out. The Serra da Capivara National Park (Piauí State) has numerous sites with remains of the ancient presence of human beings. ${ }^{13}$ Due to the great archaeological value, the Serra da Capivara National Park was inscribed on World Heritage List by UNESCO (United Nations Educational, Scientific and Cultural Organization). Another place of interest is the Xique-Xique Archaeological Site (Rio Grande do Norte State). There, the wall paintings depict chronological sequences as if telling a story, for example sex scenes and then birth. ${ }^{14-15}$

There are few works in the literature reporting on the use of LIBS applied to studies of wall paintings. The work of Brysbaert et al. ${ }^{16}$ was focused on the use of LIBS to determine the elemental content of painted plaster from Eastern Mediterranean Bronze Age, in an effort to identify the types of pigment and material used and to assess the potential of the technique in comparison with other analytical techniques. For the best of our knowledge, no works can be found in the literature using LIBS to analyze a complex sample such as prehistoric rock art wall paintings.

Contrasting with the instrumental simplicity of the technique, the LIBS spectrum is usually very complex, and may contain thousands of spectral emission lines. One of the major difficulties in analyzing wall paintings is to distinguish the pigment from the wall matrix, especially when the samples show very irregular surface, as in the case of the samples analyzed in this work. Another difficulty is to identify the superimposed layers and their composition. These layers can be produced by $(i)$ impurities deposited on the rock over the centuries, (ii) ink and (iii) the rock substrate. It is noteworthy that the identification of each layer must be done carefully because the thickness of the pigment is not uniform. Each new archaeological sample with these characteristics becomes a new challenge for the analyst as the depth profile composition and its associated emission spectra, revealed pulse after pulse of the laser, cannot be predicted a priori.

In this work, it is demonstrated that the main difficulties associated with the depth profile studies of this kind of sample can be circumvented with the use of conventional multivariate statistical data analysis techniques, such as principal component analysis (PCA). ${ }^{17-21}$

The use of pattern recognition methods, such as PCA, in LIBS spectra has been described in the literature to discriminate different materials in archeological samples. ${ }^{22}$ Duchêne et al. ${ }^{23}$ applied soft independent modeling of class analogy (SIMCA) and least-squares discriminant analysis (PLS-DA) in a cultural heritage application. A reference database composed of 30 commercial pigments traditionally used in murals and prepared with fresco tempera and oil techniques following ancient recipes was employed to evaluate the potential of these chemometric techniques for identification of pigments and painting techniques. SIMCA and PLS-DA showed correct classification for 81 and $99 \%$ of the samples, respectively.

In the present work, PCA was not only used to distinguish different materials (the painting from the rock), but also to help to conduct a study in depth profiling in prehistoric rock painting. PCA was important to evaluate the appropriate energy to reveal each layer, then to identify the layers present in the prehistoric samples, and finally to determine their major components. Furthermore, PCA was also important to indicate which of the collected spectra better represent the composition of the pigment (for study the composition of the pigment more reliable) since the layers in the sample are irregular and spectra obtained in painting region may also contain information from the rock.

\section{Experimental}

\section{Surrogate sample of wood painting for depth profile screening studies}

A surrogate historical wood painting was produced as shown in Figure 1. This figure indicates the locations where the laser was pulsed: (1) one layer - base (rabbit glue and carbonate), (2) two layers - the first layer is the armenian bole and the second is the base, (3) three layers - the first is gold leaf, the second is armenian bole and the third is base, and (4) four layers - the first layer is red paint, the second is gold leaf, the third is armenian bole and the last is the base. The 
painting allows the LIBS access to individual layers and also to the superimposed layers of the different materials.

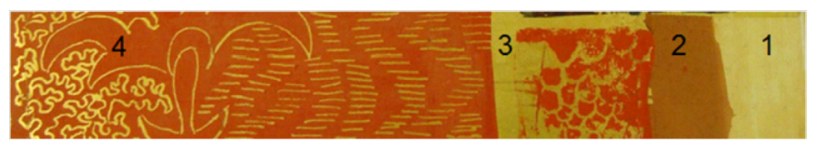

Figure 1. Surrogate wood paintings. Location 1: one layer - base (rabbit glue and carbonate). Location 2: two layers - the first layer is the armenian bole and the second is the base. Location 3: three layers - the first is gold leaf, the second is armenian bole and the third is the base. Location 4: four layers - the first layer is red paint, the second is gold leaf, the third is armenian bole and the last is the base.

\section{Archeological wall painting samples}

Fragments of wall paintings found in two archaeological sites: (i) Toca da Extrema II Archaeological Site (Piauí State) (Figure 2a), which is one of the numerous sites presents in the Serra da Capivara National Park, and (ii) Xique-Xique Archaeological Site (Rio Grande do Norte State) (Figure 2b) were investigated. A distance of approximately $1200 \mathrm{~km}$ separates the archaeological sites of Toca da Extrema II and Xique-Xique. The fragment from Toca da Extrema II Archaeological Site was found after an excavation. The fragment from Xique-Xique Archaeological Site was released from cavern walls and was found on the ground. On the wall of the cave, there is a fractured region in which the size and format fit the one of the painted fragment. In both fragments, the paintings represent part of an anthropomorphic figure.
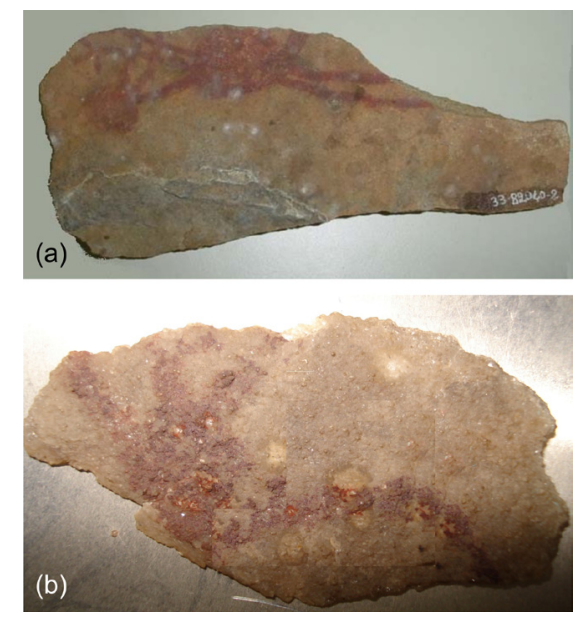

Figure 2. Prehistoric painting samples from (a) Toca da Extrema II Archaeological Site and (b) Xique-Xique Archaeological Site.

\section{Instrumentation}

A time-resolved echelle based LIBS system, assembled in the laboratory, with a pulsed Nd:YAG laser, $(20 \mathrm{~Hz}$, $1064 \mathrm{~nm}$, pulse with FWHM (full width at half maximum) of $5.2 \mathrm{~ns}$ and maximum pulse energy of $120 \mathrm{~mJ}$ ) and an ICCD (intensified charge-coupled device) detector, was employed for spectral acquisition. A schematic diagram of the LIBS system is illustrated in Figure 3. The energy of the pulse was varied by selecting an appropriate delay time between the flash lamp pulse and the Q-switch triggering. The pulse energy and its repeatability (always lower than $5 \%$ ) have been measured for each selected delay.

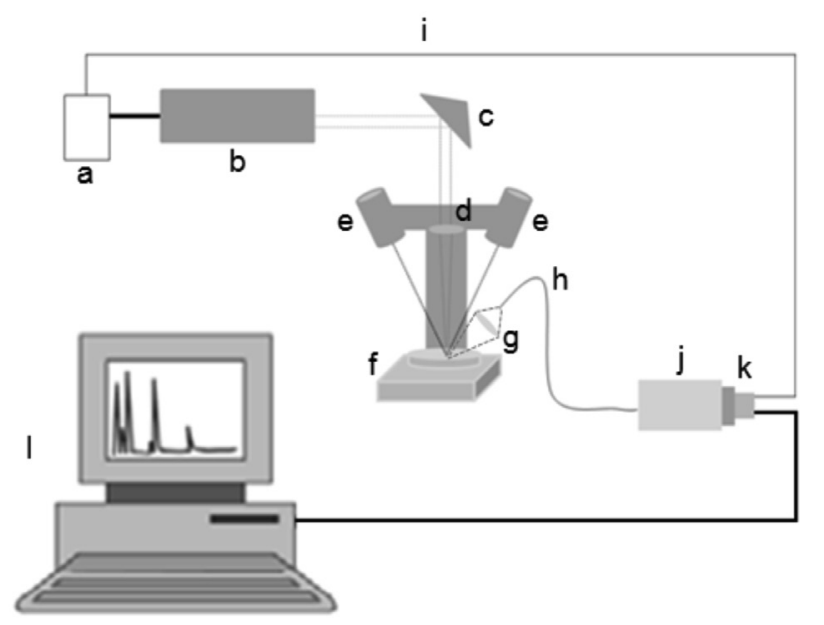

Figure 3. Scheme of the LIBS system: (a) laser source and cooler, (b) pulsed laser head, (c) mirror, (d) focusing lens, (e) laser pointer, (f) sample, (g) collecting optics, (h) optical fiber, (i) detector trigger signal, (j) wavelength selector, (k) detector array and (1) microcomputer.

The radiation emitted by the plasma was collected by a quartz biconvex lens, with a focal length of $10 \mathrm{~cm}$, coupled to an optical fiber of $50 \mu \mathrm{m}$ diameter (Ceram Optec), which delivers it to an echelle spectrometer (Mechelle 5000, Andor Tehnology) for detection by an ICCD camera (iStar DH734, Andor Technology). The emission signals were identified using the NIST (National Institute of Standards and Technology) Atomic Spectra Database Lines Form. ${ }^{24}$

The spectra were displayed and analyzed using Andor iStar software, version 4.1.0.0 12C. To avoid the effect of high background intensity caused by the continuum emission existing in the first moments of the plasma lifetime, a delay of $500 \mathrm{~ns}$ was employed before starting the spectral acquisition. After the delay, the emitted radiation was integrated for a $1 \mu$ s time interval. The detector gain was set 150 .

The sample to lens distance was kept at $9.7 \mathrm{~cm}$ to avoid the air breakdown. This arrangement produces a spot of an area approximately equal to $0.25 \mathrm{~mm}^{2}$ on the sample surface. The rocks containing the prehistoric paintings show very irregular surfaces, as previously commented. To assure the sample to lens distance at any location, the system presented in Figure 3 was employed. Two laser pointer 
beams were aligned in such way that they are merged on the sample surface at the selected sample to lens distance. The samples stand in a platform that can be moved vertically. Before measurement in a new location, the sample was moved up or down until the laser pointer beams are merged again one each other on the sample surface.

For the most employed pulse energy $(20.3 \mathrm{~mJ})$ in this work, an energy density of $8.2 \mathrm{~J} \mathrm{~cm}^{-2}$ on the targeted area can be estimated.

\section{Measurements}

Preliminary screening experiments were carried out on the surrogate historical wood painting to approximate the best instrumental conditions used to perform in-depth profile analysis. In this surrogate material, it is possible to sample the four different layers both individually and in-depth profile studies using successive laser pulses on the same multilayer location. Therefore, after the spectral comparison using PCA, it is possible to associate the layer sampled by each laser pulse of a sequence of pulses fired in the same local. The use of archaeological samples in the screening experiments is not recommended as it could cause a relatively large damage on those rare and irreplaceable materials.

Although the subtracts are different (wood and rock), these experiments were useful to evaluate the minimum pulse energy sufficient to produce intense spectra, while being also capable of identify the layers of paint. The pulse energies tested were: 20.3, 12.3 and $5.36 \mathrm{~mJ}$. Two consecutive pulses of each energy were applied in three different locations of the regions 1, 2 and 3 (Figure 1). Five consecutive pulses were applied in three different locations of region 4 .

In the case of the rock fragments with wall paintings, 8 consecutive laser shots were fired on 16 locations ( 8 in the pigment area and 8 in the substratum area).

\section{Principal component analysis (PCA)}

Principal component analysis (PCA) is a well-known tool in multivariate data analysis for visualizing information in large data sets. ${ }^{25}$ PCA can be used to simplify data interpretation by reducing the number of variables into a smaller number of orthogonal variables, which are linear combinations of the original variables (wavelength), and by maximizing the variance of the original variables accounted within them, thereby displaying most of the original variability with fewer dimensions. The projections (new coordinates) of the objects on this new axis (PCs) are denominated scores. The coefficients of the linear combination (loadings) account for the influence of each original variable on each PC. Thus, the graphical presentation of the pair-wise components (score plots) allows visualizing the natural distribution of the samples, indicating the similarity among the samples and allowing different groups of samples to be identified. In this work, PCA was employed to verify the presence of clusters related to the depth profile analysis of the samples. In this way, the clusters could be attributed to distinct layers of the sample. The loading graphs were employed to identify the elements responsible for differentiation of the clusters observed. The data matrix was composed of the LIBS spectra set of series of pulses fired in pre-selected regions of the sample. All data were mean centered before processing. Various pre-processing techniques were evaluated, such as normalization, standard normal variate (SNV) and a combination of the above. ${ }^{26-27} \mathrm{PCA}$ and pre-processing were made by using in the Unscrambler ${ }^{\mathrm{TM}} 9.8$ (CAMO Software, Norway) chemometric software.

\section{Results and Discussion}

\section{Surrogate wood painting experiments}

Figure 4 shows the plot of the scores for PC1, PC2 and PC3, which respectively explains 39,34 and $13 \%$ of the spectral data variance obtained using the laser pulse energy equal to $20.3 \mathrm{~mJ}$. The spectra of the first laser shots fired in regions 3 and 4 are grouped in two distinct clusters. The spectra obtained with the second laser shots fired in these two regions and the other spectra (obtained in regions 1 and 2) are similar, indicating that the second pulses had penetrated the paint layer reaching the base (rabbit glue) and bole. Using energy equal to $5.4 \mathrm{~mJ}$, the spectra obtained were noisy and the PCA analysis did not show any discrimination. The score plot of the spectral data obtained using energy equal to $12.3 \mathrm{~mJ}$ is similar to Figure 4, showing a discrimination of the spectra obtained with the first pulses in regions 3 and 4. These spectra, however, present only half of the intensity of those spectra obtained using energy at $20.3 \mathrm{~mJ}$. These experiments show the possibility of discriminating among the layers of paint, obtaining intense spectra when pulses of $20.3 \mathrm{~mJ}$ are employed. Using this information as a guide, this energy was also selected for the measurements of the prehistoric paintings. Of course, the painting composition and substrate of the painted rock samples are distinct from the surrogate samples of painted wood employed in this preliminary studies. However, it was possible to approximate a good starting point for the laser energy and other instrumental parameters to be employed when depth profile studies of painted surfaces are aimed. 


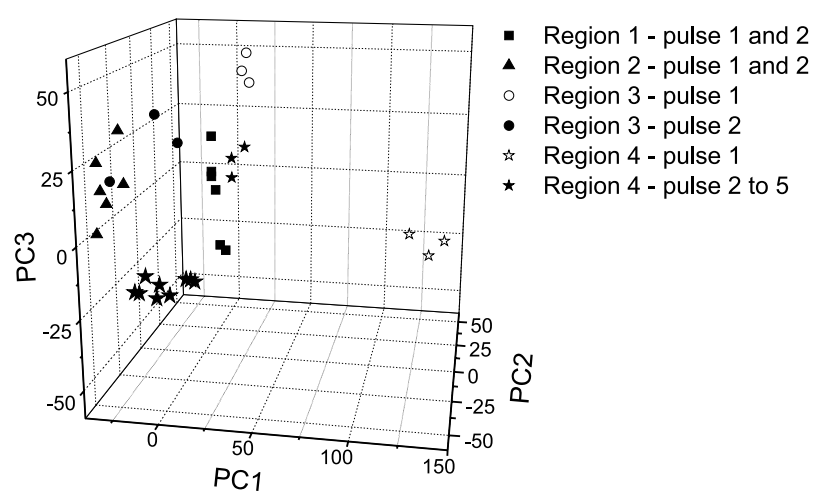

Figure 4. Score plot of a PCA carried on the LIBS spectral data obtained employing laser pulses with energy of $20.3 \mathrm{~mJ}$ fired on several regions of the surrogate wood painting sample.

\section{Prehistoric painting from the Toca da Extrema II Archaeological Site}

Principal component analysis was performed in the spectra set after applying different pre-processing techniques. The best results were obtained using SNV, which was primarily developed to minimize unwanted variations due to scatter effects caused by particle size distribution. Although these scattering effects can be present in a LIBS spectrum, their correlation with particles ejected from the sample surface has not yet been established. On the other hand, the spectra set obtained shows additive and multiplicative features similar to those caused by the scattering phenomena. Therefore, all results presented in the next sections were obtained using SNV. The multiplicative signal correction (MSC) algorithm, also found in the Uncrambler ${ }^{\mathrm{TM}}$ software, could be used for the same purpose. However, in contrast with the SNV approach, a model needs to be constructed and saved to be employed in the correction of new spectra. A principal component analysis was performed with the whole spectra set obtained by firing 8 consecutive pulses $(20.3 \mathrm{~mJ})$ in each one of the 16 locations. PC1 and PC2 explain 37 and $20 \%$, respectively, of the data variance. The analysis of the other high order PCs does not show any evidence of clusters or any other relevant information. PC2 discriminates the spectra obtained with the laser shot fired in the painting region (negative scores) from those obtained in the substrate region (positive scores). There is a tendency of the spectra obtained in deeper layers of the painting region to present scores less negative in PC2 (Figure S1 in the Supplementary Information (SI) section). In fact, from the fourth pulse, the painting is penetrated and the spectra also contain information associated with the substrate composition.

Therefore, a new PCA was carried out using only the spectra obtained with the first three pulses and the resulted score plot is shown in Figure 5a. PC1 and PC2 explain
35 and $31 \%$, respectively, of the total spectral variance. The first component discriminates the pigment region from the substrate region. The spectra of the pigment present more negative score values in $\mathrm{PC} 1$. The spectra for the first pulses (obtained from the rock and from the pigment locations) present similar scores in PC2. The analysis of the other high order PCs does not show any evidence of clusters or any other relevant information. An interesting aspect is related to the spectra set obtained for the first pulses (fired on the substrate and on the pigment locations), which present similar scores in PC2. It indicates the existence of an outer layer with similar composition. This fact is a novelty for archeology because it may be related to a human intervention occurred after the completion of paintings. The analysis of this layer can (in the future) give information on the technological phase for paintings found at this archeological site. Figure $5 \mathrm{~b}$ and Figure $5 \mathrm{c}$ show the PC1 and PC2 loading plot of PCA carried out on the spectral data obtained with the first three consecutive pulses. The peaks of this graph are related to the emission wavelengths that contribute to PC1 and PC2. Spectral assignments were carried out for the higher loadings in order to determine which chemical elements are causing the higher values. PC1 is composed negatively by iron emission lines and positively by silicon, titanium and calcium emission lines. Thus, the difference between the spectra for the pulses carried out on the painting and on the substrate is the result of the higher concentration of iron in the pigment and higher concentrations of silicon, titanium and calcium in the substrate. Results of energy dispersive X-ray fluorescence spectrometry confirm the presence of titanium and calcium in the substrate. The PC2 loadings can be associated to the presence of $\mathrm{Ca}$ I and $\mathrm{Ca}$ II lines with positive signs and of $\mathrm{Ti}$ I and Ti II lines with negative signs. Thus, the first layer recovering the painting and the rest of the rock substrate are rich in calcium. This could be attributed to a layer of impurities deposited on the rock and on the painting surface over the centuries or could be due to a human intervention.

To determine the elements present in the pigment, only the three spectra that exhibit the most negative scores in PC1 were analyzed as these spectra are the ones showing the greater difference in relation to the rock substrate. Therefore, it is possible to ensure that the spectral information present in those spectra is only related to the pigment. Due to the variation of the painting thickness, other spectra obtained in the pigmented region could present features also associated with the rock substrate. Therefore, the analysis could be fail if based on this contaminated information. This fact enhances the advantages of the multivariate analysis applied to the LIBS data set obtained from archaeological samples. 

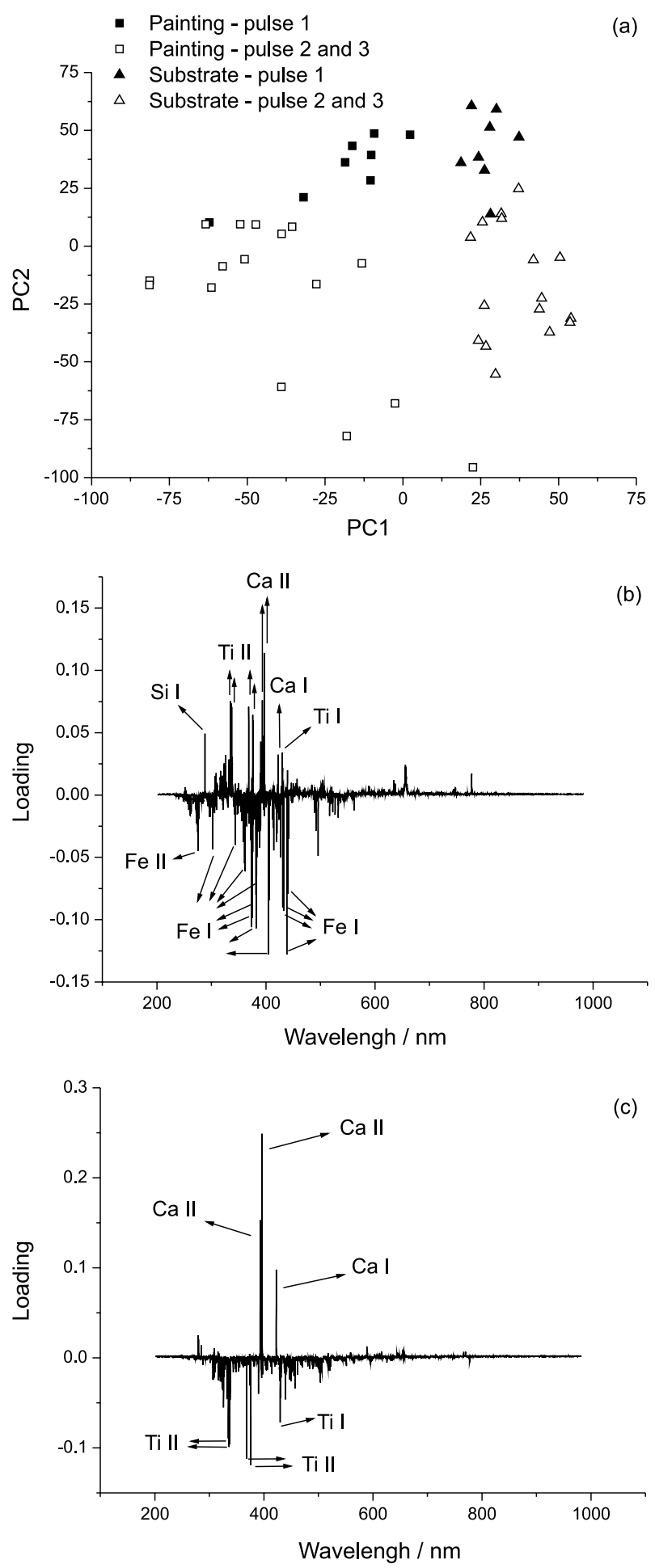

Figure 5. Results of PCA carried on the LIBS spectra set of Toca da Extrema II Archaeological Site painting obtained with the first three consecutive laser pulses: (a) score plot, (b) PC1 loading plot and (c) PC2 loading plot.

The analysis of the wavelength ranges 258-264, 271-275, 293-302 and 321-323 nm containing features of the iron element confirmed the presence of this element in the pigment, as expected (Figure S2 in the SI section). ${ }^{16,24}$
The presence of iron made possible to identify the ochre red pigment which is based on hematite $\left(\mathrm{Fe}_{2} \mathrm{O}_{3}\right)$, the only red pigment easily available at those times. ${ }^{16}$ The other elements found were $\mathrm{Al}, \mathrm{Ca}, \mathrm{Mg}, \mathrm{Mn}, \mathrm{Si}$ and Ti. The spectra showed strong emission of calcium at 422.67 and $396.84 \mathrm{~nm}$. The presence of calcium may result from mixing pigment with calcium oxide or could be the result of rituals involving bones.

\section{Prehistoric painting from Xique-Xique Archaeological Site}

In this painting, it was also observed that the fourth laser pulse passes through the paint layer reaching the rock substrate. Figure 6a shows the score plot of PCA performed with the LIBS spectra of the first three pulses, explaining the data variance of 38 and $13 \%$ for PC1 and $\mathrm{PC} 2$, respectively. The analysis of PCs of higher order (as reported for the Toca da Extrema II sample) did not show any important cluster or relevant information. The spectra
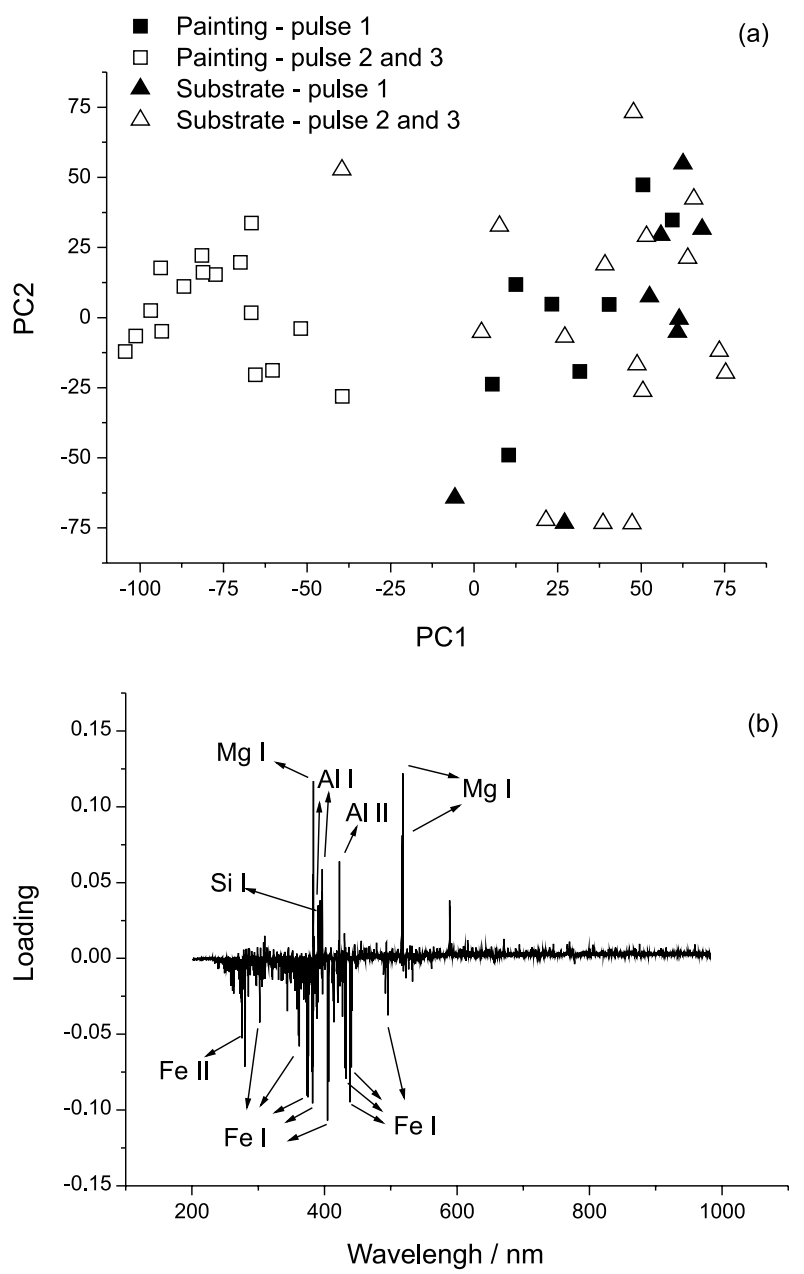

Figure 6. Results of PCA carried on LIBS spectra of the first three consecutive laser pulses fired on the prehistoric painting from the Xique-Xique Archaeological Site (a) PCA score plot and (b) PC1 loading plot. 
obtained by the first pulses (on the painting and on the substrate) cluster with those obtained by the second and the third pulses fired on the substrate. This may be due to geological processes caused for instance by wind that might have deposited a layer of impurities on the wall of the cave, with a composition similar to the substrate. It should be highlighted that both archaeological sites from where the samples were obtained are exposed to the weather conditions, in contrast with most of the franc-cantarabic sites where the paintings are found in closed chambers, preserved from the external environment.

The analysis of the loading plot (Figure 6b) revealed that $\mathrm{PC} 1$ is negatively influenced by iron lines and positively by magnesium and aluminum lines. This indicates a higher concentration of iron in the spectra of the pigment. The presence of magnesium and aluminum in the composition of the substrate was confirmed by measurements of scanning electron microscopy coupled with energy dispersive X-ray (SEM/EDX) ${ }^{28}$ The analyses of the three spectra with more negative scores in PC1 (Figure 6a) revealed the presence of $\mathrm{Al}, \mathrm{Ca}, \mathrm{Fe}, \mathrm{Mg}, \mathrm{Mn}, \mathrm{Ti}$ and $\mathrm{Si}$. Strong emission lines of iron become possible again to identify the ochre red pigment, as expected. Strong emissions of calcium at 422.67 and $396.84 \mathrm{~nm}$ were also found in this painting.

\section{Conclusions}

Due to the complexity of LIBS spectra in the archaeological samples analyzed in this work, the use of multivariate techniques such as principal component analysis is essential to accomplish with depth profile studies in irregular surfaces, like the rock substrate and the painting layers found in the samples studied in this work. PCA was also useful for the identification of elements that could differentiate among the substrate, the painting and the most outer layer found over the entire sample.

PCA revealed the presence of an outer first layer recovering all the sample surface in both archeological sites. In the sample from the Toca da Extrema II Archeological Site, this first layer is richer in calcium than the substrate or the painting layer. This could be attributed to a layer of impurities deposited on the rock and on painting surface over the centuries or could be due to a human intervention. The analysis of the sample from Xique-Xique Archaeological Site shows that the first layer found on the entire sample surface presents composition similar to the substrate. This may be due to geological processes caused for instance by wind that might have deposited a layer of impurities on the wall of the cave, with a composition similar to the surround rocks. Regarding the finding of a first layer of impurities in the painting region, there is the possibility of two approaches aiming to the sample study: if the goal is the determination of the age of the application of the paint in the rock wall, the first layer should be removed. In contrast, if the goal is to study the evolution of the deposition process of natural exogenous agents, the transformation of the rock substrate that contains the paintings or the deposition of chemical components, the determination of the first layer composition becomes essential.

Using the PCA score plot, it was possible to identify unequivocally the spectra belonging only to the pigment layer. This is easily done by a previous analysis of the score plot and by searching for the spectra set that shows the highest possible difference from those attributed to the substrate (measured by the distance among the spectral scores in the suitable PC). On adopting this procedure, a further analysis of the layer of interest can be made in the absence of possible concomitants, avoiding unwanted mistakes in the determination of its elemental composition.

The presence of iron made possible to identify the hematite $\left(\mathrm{Fe}_{2} \mathrm{O}_{3}\right)$ based ochre red pigment which was the only red pigment easily available at the time the paintings were created. Strong emission lines of calcium are present in the paintings in both samples. Considering the distance between the archeological sites of more than $1000 \mathrm{~km}$, this could be attributed to a technological skill shared by people who made the paintings and in accordance with the fact that pigment was mixed with calcium oxide or could be the result of rituals involving bones. The discovery of painted bones in both sites corroborates the last hypothesis.

Although in this work the results of the screening experiments carried on the surrogate sample of painted wood had been employed only to guide the studies of the prehistoric rock painting, they also demonstrate that LIBS can help in the identification of the materials employed in real paintings and help in the restoration in Brazil.

In conclusion, careful interpretation of the results obtained by multivariate analysis of LIBS spectral data sets of painting samples of historical interest is highly promising for archaeological science.

\section{Supplementary Information}

Supplementary data (Figures S1 and S2) are available free of charge at http://jbcs.sbq.org.br as a PDF file.

\section{Acknowledgments}

The authors acknowledge the support of the Instituto Nacional de Ciências e Tecnologias Analíticas Avançadas (INCTAA), Instituto de Ciência e Tecnologia de Arqueologia, Paleontologia e Ambiente do Semiárido 
do Nordeste do Brasil (INAPAS), Conselho Nacional de Desenvolvimento Científico e Tecnológico (CNPq), Fundação de Amparo à Pesquisa do Estado de São Paulo (FAPESP), Coordenação de Aperfeiçoamento de Pessoal de Nível Superior (CAPES/PROCAD), Financiadora de Estudos e Projetos (FINEP) and Fundação de Amparo à Pesquisa do Estado de Pernambuco (FACEPE).

\section{References}

1. Agresti, J.; Mencaglia, A. A.; Siano, S.; Anal. Bioanal. Chem. 2009, 395, 2255.

2. Cuñat, J.; Fortes, F. J.; Laserna, J. J.; Anal. Chim. Acta 2009, $633,38$.

3. Goujon, J.; Giakoumaki, A.; Piñon, V.; Musset, O.; Anglos, D.; Georgiou, E.; Boquillon, J. P.; Spectrochim. Acta, Part B 2008, 63, 1091.

4. Song, K.; Lee, Y.; Sneddon, J. In Advances in Atomic Spectroscopy, vol. 7; Elsevier Science: Amsterdam, 2002, ch. 6.

5. Trevizan, L. C.; Santos Jr., D.; Samad, R. E.; Vieira Jr., N. D.; Nomura, C. S.; Nunes, L. C.; Rufini, I. A.; Krug, F. J.; Spectrochim. Acta, Part B 2008, 63, 1151.

6. Lee, W. B.; Wu, J. Y.; Lee, Y.; Sneddon, J.; Appl. Spectrosc. Rev. 2004, 39, 27.

7. Pasquini, C.; Cortez, J.; Silva, L. M. C.; Gonzaga, F. B.; J. Braz. Chem. Soc. 2007, 18, 463.

8. Winefordner, J. D.; Gornushkin, I. B.; Correll, T.; Gibb, E.; Smith, B. W.; Omenetto, N.; J. Anal. At. Spectrom. 2004, 19, 1061.

9. Anzano, J. M.; Villoria, M. A.; Ruíz-Medina, A.; Lasheras, R. J.; Anal. Chim. Acta 2006, 575, 230.

10. Fortes, F. J.; Cortés, M.; Simón, M. D.; Cabalín, L. M.; Laserna, J. J.; Anal. Chim. Acta 2005, 554, 136.

11. Gonzaga, F. B.; Pasquini, C.; Spectrochim. Acta, Part B 2008, $63,1268$.

12. Harmon, R. S.; DeLucia, F. C.; McManus, C. E.; McMillan, N. J.; Jenkins, T. F.; Walsh, M.E.; Miziolek, A.; Appl. Geochem. 2006, 21, 730 .

13. Guidon, N.; Vidal, I. A.; Salvia, E. S. L.; Felice, G. D.; Melo, P. P.; Buco, C.; Fumdhamentos 2002, II, 105.
14. Martin, G.; Pré-História do Nordeste do Brasil, 3a. ed.; Editora Universitária UFPE: Recife, PE, Brasil, 1999.

15. Martin, G.; Fumdhamentos 2007, V, 6.

16. Brysbaert, A.; Melessanaki, K.; Anglos, D.; J. Archaeol. Sci. 2006, 33, 1095.

17. Silva, M. J.; Cortez, J.; Pasquini, C.; Honorato, R. S.; Paim, A. P. S.; Pimentel, M. F.; J. Braz. Chem. Soc. 2009, 20, 1887.

18. Pontes, M. J. C.; Cortez, J.; Galvão, R. K. H.; Pasquini, C.; Araújo, M. C. U.; Coelho, R. M.; Chiba, M. K.; Abreu, M. F.; Anal. Chim. Acta 2009, 642, 12.

19. Death, D. L.; Cunningham, A. P.; Pollard, L. J.; Spectrochim. Acta, Part B 2009, 64, 1048.

20. Osticioli, I.; Mendes, N. F. C.; Nevin, A.; Gil, F. P. S. C.; Becucci, M.; Castellucci, E.; Spectrochim. Acta, Part A 2009, 73,525 .

21. Gottfried, J. L.; De Lucia Jr., F. C.; Munson, C. A.; Miziolek, A. W.; Spectrochim. Acta, Part B 2007, 62, 1405.

22. Colao, F.; Fantoni, F.; Ortiz, P.; Vazquez, M. A.; Martin, J. M.; Ortiz, R.; Idris, N.; Spectrochim. Acta, Part B 2010, 65, 688.

23. Duchêne, S.; Detalle, V.; Bruder, R.; Sirven, J. B.; Curr. Anal. Chem. 2010, 6, 60.

24. NIST Atomic Spectra Database Lines, http://physics.nist.gov/ PhysRefData/ASD/lines_form.html accessed in June 2010.

25. Naes, T.; Isaksson, T.; Fearn, T.; Davies, T.; A User-Friendly Guide to Multivariate Calibration and Classification; NIR Publications; Chichester, 2002.

26. Barnes, R. J.; Dhanoa, M. S.; Lister, S. J.; Appl. Spectrosc. 1989, 43, 772 .

27. Rinnan, A.; van den Berg, F.; Engelsen, S. B.; TrAC, Trends Anal. Chem. 2009, 28, 1201.

28. Khoury, H. J.; Guzzo, P. L.; Sullasi, H. L.; Barreto, S. B.; Pessis, A. M.; Proceedings of The XI Latin American Seminary of Analysis by X-Ray Techniques, Cabo Frio, RJ, Brazil, 2008.

Submitted: May 28, 2011

Published online: April 24, 2012

FAPESP has sponsored the publication of this article. 